\title{
BMJ Open Impact of clinical leadership in teams' course on quality, efficiency, responsiveness and trust in the emergency department: study protocol of a trailing research study
}

\author{
Sissel Eikeland Husebø, ${ }^{1,2}$ Øystein Evjen Olsen ${ }^{3,4}$
}

To cite: Husebø SE, Olsen ØE. Impact of clinical leadership in teams' course on quality, efficiency, responsiveness and trust in the emergency department: study protocol of a trailing research study. BMJ Open 2016;6: 011899 .

doi:10.1136/bmjopen-2016011899

- Prepublication history for this paper is available online. To view these files please visit the journal online (http://dx.doi.org/10.1136/ bmjopen-2016-011899).

Received 15 March 2016 Revised 17 June 2016 Accepted 22 July 2016

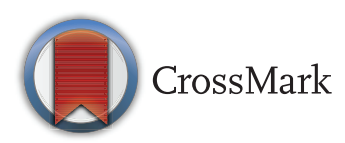

For numbered affiliations see end of article.

Correspondence to Dr Sissel Eikeland Husebø; sissel.i.husebo@uis.no

\section{ABSTRACT}

Introduction: Clinical leadership has long been recognised as critical for optimising patient safety, quality of care and interprofessional teamwork in busy and stressful healthcare settings. There is a need to compensate for the absence of the conventional mentor-to-apprentice transfer of clinical leadership knowledge and skills. While young doctors and nurses are increasingly proficient in medical, surgical and technical skills, their training in, and knowledge of clinical leadership skills, is not adequate to meet the demands for these non-technical skills in the emergency department. Thus, the purpose of the paper is to present and discuss the study protocol of clinical leadership in a course for teams that aims to improve quality, efficiency, responsiveness of healthcare services and collegial trust in the emergency department.

Methods and analysis: The study employs a trailing research design using multiple quantitative and qualitative methods in the summative (pretest and posttest) and formative evaluation. Quantitative data have been collected from a patient questionnaire, the emergency departments' database and by the observation of team performance. Qualitative data have been collected by shadowing healthcare professionals and through focus group interviews. To ensure trustworthiness in the data analysis, we will apply member checks and analyst triangulation, in addition to providing contextual and sample description to allow for evaluation of transferability of our results to other contexts and groups.

Ethics and dissemination: The study is approved by the ethics committee of the western part of Norway and the hospital. The study is based on voluntary participation and informed written consent. Informants can withdraw at any point in time. The results will be disseminated at research conferences, peer review journals and through public presentations to people outside the scientific community.

\section{INTRODUCTION}

Clinical leadership (CL) has long been recognised as critical for optimising patient

\section{Strengths and limitations of this study}

- The strengths of trailing research design is the flexible use of knowledge collected through participation and dialogue in combination with knowledge acquired and interpreted through traditional scientific methods.

- Participatory validity will be obtained by participant confirmation of the 'shadowing' transcription and feedback on results in the dialogue meetings. Rigour will be achieved by the transparency with which the data are generated and how events are questioned and interpreted in the formative and summative evaluation.

- The pretest and post-test design used in this study has several weaknesses. Other events (history) between the pretest and post-test, which represent a threat to internal validity, may also cause an effect that has alternative explanations.

- The effectiveness of the training programmes is more difficult to measure because a wide range of variables unrelated to the training intervention can mediate both the training process and the outcome.

- The content, duration and frequency of the clinical leadership in teams (CLT) course may influence the effectiveness of the intervention.

safety, quality of care and interprofessional teamwork in busy and stressful healthcare settings. ${ }^{1}{ }^{2}$ Effective CL is a prerequisite for understanding the complex system of care for the benefit of patients and ensuring healthy workplaces. ${ }^{3}{ }^{4}$ Conversely, ineffective CL has a negative impact on the healthcare workers and standard of care and can lead to adverse events. ${ }^{4} 5$ There is a need to compensate for the absence of the conventional mentor-to-apprentice transfer of CL knowledge and skills. While young doctors and nurses are increasingly proficient in medical, surgical and technical nursing skills, their training in, and knowledge of CL skills, is 
not adequate to meet the demands for these nontechnical skills in the emergency department (ED) and other wards and work environments in a modern hospital. ${ }^{6-9}$ Nevertheless, opportunities in everyday clinical practice to acquire, practise and receive feedback on $\mathrm{CL}$ skills remain scarce. ${ }^{10}$ Strategies to promote CL skills should include clinical supervision programmes, interprofessional collaboration and the development of skills. ${ }^{11-13}$ Previous CL programmes have demonstrated development of self-reported and observer-reported behaviours of CL competencies, ${ }^{14}$ improved safety and quality of care, ${ }^{11}$ development of individual skills and influence on workplace culture. ${ }^{15} 16$ The training programmes have centred on leadership behaviours/traits and competencies; however, evidence of the impact of such programmes on the operational level is scarce. ${ }^{4} 17$

CL is a poorly understood concept that lacks a standard definition. ${ }^{4}{ }^{17}$ Mannix et at $t^{4}$ suggested that there exists an almost taken-for-granted stance about how CL can be characterised. Others ${ }^{18}$ have stated that CL is fostered in an environment where the staff is empowered and where there is a vision for the future. Cook and Holt ${ }^{19}$ concluded that effective CL requires leadership skills for team building, confidence and respect for others. A review presents a definition of CL that emphasises attributes such as a drive towards improved service and management of teams to provide excellence in patient care. ${ }^{17}$ In Mannix et $a l,{ }^{4}$ only two studies have developed a definition of CL from their respective findings. One of the studies ${ }^{20}$ refers to Harper, ${ }^{21}$ who describes a clinical leader as one who possesses clinical expertise in a specialty practice area and who uses interpersonal skills to enable nurses and other healthcare providers to deliver quality patient care.

According to Howieson and Thiagarajah, ${ }^{17}$ although the CL literature in healthcare programmes seems to be extensive, problems exist. Research on CL has focused on studying trait-based and behavioural-based competency models. Howieson and Thiagarajah ${ }^{17}$ claim there are several concerns with this approach, such as centredness on recommended behaviour/traits and competencies, losing sight of the contextual and situational nature of CL, gaps between the perceptions of leadership embodied in competency frameworks and the perceptions of leaders themselves. This approach does not inform what constitutes effective CL behaviours in different contexts. Consequently, the social influence process of CL cannot be fully understood unless a more discursive approach is applied.

Hence, there is a need for more research to determine if a course in clinical leadership in teams (CLT) improves the quality of healthcare services in the ED. The CLT course is an institutionalised approach to improve value-based non-technical skills of clinical personnel. It takes a horizontal and operational approach, focusing on clinical management and coordination of the interprofessional team in a realistic, routine-based patient-centred context. A team's approach to CL has been taken because all clinical personnel operate in an environment in which they are influenced by, and influence others through their actions and decisions. Patient safety is highly dependent on the level of collaboration between clinical personnel in all settings. CL therefore requires leadership skills for interdisciplinary team building, confidence in and respect for others and a combination of expertise and communication skills.

The aim of the study is to evaluate the impact of a CLT course in terms of quality, efficiency, responsiveness of healthcare services and interprofessional trust in the ED.

\section{Theoretical concepts}

To address the aim of the hospital improvement process related to clinical quality in the $\mathrm{ED}$ and $\mathrm{CL}$, in the context of taking responsibility for conducting medical and nursing practice with a patient-centred perspective, CL needs to be redefined. The working group responsible for developing the course decided that the following four bedside values would underpin the theoretical foundation of the curriculum and evaluation of the course's impact: ${ }^{22}$ trust, quality, responsiveness and efficiency. These values were considered to provide the necessary platform for the translation of principles by combining the values of the hospital with the concept of CL to address the needs of the ED. Definitions of these values are outlined elsewhere. ${ }^{13}$

\section{METHODS AND ANALYSIS}

\section{Study design}

The current study employs a trailing research design with pretest and post-test, using quantitative and qualitative methods in the evaluation. ${ }^{22}$ Trailing research is a dialogue-based process analysis and an appropriate research method when the purpose is to have a constructive dialogue with the participants and stakeholders. ${ }^{23} 24$ They will be able to influence what is evaluated, and also the methods and how the data are interpreted and applied. ${ }^{25}$ In the current study, trailing research was considered suitable because the researcher had no explicit stake in the outcome of the change or responsibility in any way for securing successful results. Participatory action research (PAR), in comparison, assumes the researcher is also influencing and involved in the change process. ${ }^{23}$ The objective is learning and evaluation created through participants' and researchers' reflections (table 1).

In phase 1 , the planning of the study and the CLT course, it was important to clarify the study design and outcomes in cooperation with the ED. ${ }^{24} \mathrm{~A}$ pilot test of the CLT course was conducted and was followed with an evaluation and refinement of the course. ${ }^{22}$ Additionally, parts of the CLT course were tested in a simulation setting. In phase 2, the CLT course was executed and the first author gave feedback on the preliminary findings in dialogue meetings. The objective of these meetings was to reflect and gain experiential learning based 


\begin{tabular}{|c|c|}
\hline $\begin{array}{l}\text { Table } 1 \text { Characteristi } \\
\text { p.152) }\end{array}$ & $e r,{ }^{2 o}$ \\
\hline Objective & $\begin{array}{l}\text { Scientific knowledge } \\
\text { Provide real-time feedback to } \\
\text { organisations } \\
\text { Enable learning and } \\
\text { collaborative knowledge } \\
\text { generation }\end{array}$ \\
\hline Role of researcher & $\begin{array}{l}\text { Critical outsider yet integrated } \\
\text { insider } \\
\text { Not an active change agent and } \\
\text { has no explicit stake in change } \\
\text { outcomes } \\
\text { Dialogue partner and trustful } \\
\text { relationship with 'insiders' }\end{array}$ \\
\hline $\begin{array}{l}\text { Respondent- } \\
\text { researcher relationships }\end{array}$ & $\begin{array}{l}\text { Often formal contract based } \\
\text { Division of roles (researcher/ } \\
\text { participants/stakeholders) }\end{array}$ \\
\hline Timeframe & Contemporary \\
\hline
\end{tabular}

on the preliminary findings. ${ }^{24}$ The objective of the formative evaluation was to improve the course as it happens, based on the quantitative and qualitative data. In the next phase, the CLT course was adjusted, and the final phase was a summative evaluation of the course and the consequences of the intervention.

\section{Setting}

The current study was conducted in the ED at a university hospital in the south western part of Norway. The ED at the hospital is located in an urban setting and triages 30 000 patients per year. Every week the ED delivers emergency care to 600 patients from 18 municipalities with a population of about 350000 . The ED staff consists of 120 intensive care and registered nurses, 40 attending physicians on rotation from medical, surgical and neurological departments, and various support personnel. The ED is divided into two major care areas; the triage area with 14 beds and the treatment area with 22 beds.

The regional office of the Norwegian Board of Health Supervision conducted a follow-up evaluation of ED services at the hospital in the spring of $2013 .{ }^{26}$ The report concluded that there was insufficient number of qualified medical personnel (doctors) in the ED. The hospital responded to these conclusions by establishing a steering committee involving the hospital's top leadership. This committee established several working groups, each with a specific mandate to address the challenges the report highlighted. As a result of the proceedings of one of these groups it was concluded that there was a need to initiate a process to secure CL skills among key health personnel in the ED. The response to this conclusion was the development and implementation of the CLT course.

\section{Study participants and ethics}

Twelve nurses in charge, 40 doctors on call, 30 nurses and 400 patients admitted to the ED in the hospital were invited to participate in the pretest and post-test, respectively. The pretest was conducted in August and September 2013 and the post-test was planned for 2016. The data of the formative evaluation were collected from December 2013 to September 2015.

Participants received written and oral information about the study, and all participants willing to participate signed an informed consent form before they were enrolled in the study. Confidentiality is guaranteed. Patients admitted to the ED will be requested to participate by the nurses in the medical, surgical and neurological units 1-day after admission to the ED (box 1).

\section{Research procedures}

The current study comprises the following three components: (1) the summative evaluation, (2) the formative evaluation and (3) the CLT course (figure 1). Table 2 describe concepts, operationalisation of the concepts, the sample and data collection in the summative and formative evaluation.

\section{Summative evaluation}

The summative evaluation includes quality of care and quality of team performance, responsiveness, efficiency and interprofessional trust.

Quality is evaluated from the patient's perspective, and by observing interprofessional team performance. Quality of care is measured by a short form of the 'Quality from the Patient's Perspective (QPP) questionnaire'. ${ }^{27}$ Patients' perceptions of what constitutes quality of care are formed by their encounters with an existing care structure and by their system of norms, expectations and experiences. The questionnaire has 50 items and four dimensions: medical-technical competence of the caregivers, physical-technical conditions of the care organisation, degree of identity orientation in the attitudes and actions of the caregivers, and sociocultural

\section{Box 1 Inclusion and exclusion criteria}

\section{Inclusion criteria}

Patients admitted to the emergency department (ED) must be:

- Norwegians 18 years or older;

- Able to read and write;

- Transferred from the ED to surgical, medical or neurological units;

- Admitted to the hospital at least 24 hours ago.

Healthcare professionals:

- Doctors on call, nurses in charge and other doctors and nurses who work daily in the ED, both in ad hoc teams and in permanent positions.

Exclusion criteria

- Patients with severe illness who have been transferred from the ED to other acute care units (ie, intensive care units, cardiac units and operating theatres).

- Patients who have been diagnosed as demented or depressed by a healthcare professional and incapable of being medically fit to answer the questionnaire. 


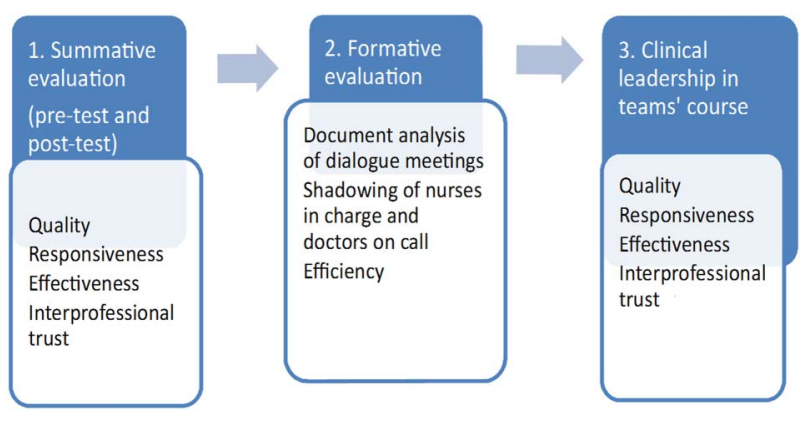

Figure 1 Components in the current study.

atmosphere of the care organisation. ${ }^{27}$ The original version in Swedish has been translated into Norwegian. $^{28}$

The quality of multidisciplinary team's performance is observed by the 'Team Emergency Assessment Measure' (TEAM) ${ }^{29}$ TEAM is a measure of team performance during medical emergencies and is constructed to measure non-technical skills in teamwork. The authors have adapted TEAM for use in non-emergency medical setting in the ED. TEAM has three subscales: the team leader (2 items), the team (7 items) and task management (2 items). The items are rated from 'never/hardly ever' (0) to 'always/nearly always' (4). TEAM has 12 items, the last of which is an overall rating scale from 1 (lowest) to 10 (highest).
Responsiveness deals with the patients' expectations and perceptions of existing care structures in healthcare and will be measured by a subscale (4 items) from the 'World Health Survey-Health System Responsiveness' (WHSHSR). ${ }^{30}$

Efficiency is measured by a variety of time variables in the ED. ${ }^{31}$ The doctor on call and the nurse in charge will simultaneously rate the level of crowding on a fivepoint Likert scale, from 'not busy' (1) to 'extremely crowded' (5). If they consider the ED crowded, the level to which crowding compromises patient safety is indicated, from strongly disagree (1) to strongly agree (5). In order to compare the provider's ability to recognise crowding, the mean ED crowding rating of the two raters will be correlated. ${ }^{32}$ To assess how the doctor on call and the nurse in charge providers perceive their ability to manage several patients at the same time, they will rate the level of multitasking on a five-point Likert scale from 'not managing the number of patients' (1) to 'managing the number of patients very well (5)'.

Interprofessional trust will be explored in the pretest and post-test to obtain a picture of how healthcare providers in the ED perceive and experience interprofessional trust. $^{33}$ Doctors on call and nurses in charge will be invited to participate in three focus group interviews (FGIs). The group format is efficient for generating dialogue, and group interaction facilitates access to the participants' thoughts and perceptions. ${ }^{33}$

Table 2 Concepts, operationalisation of the concepts, sample and data collection in the summative (pretest and post-test) and formative evaluation

\begin{tabular}{|c|c|c|}
\hline \multicolumn{3}{|c|}{ Summative evaluation (pretest and post-test) } \\
\hline Concepts & Operationalisation of the concepts & Sample and data collection \\
\hline Quality & $\begin{array}{l}\text { QPP } \\
\text { Quality of team performance }\end{array}$ & $\begin{array}{l}\text { Randomised sample; QPP questionnaire (Wilde } \\
\text { Larsson and Larsson }{ }^{27} \text { ) } \\
\text { Convenience sample on team level; 'TEAM' } \\
\text { observation (Cooper et al, 2010) }\end{array}$ \\
\hline Responsiveness & Responsiveness from the patient's perspective & $\begin{array}{l}\text { Randomised sample; WHO 'World Health Survey- } \\
\text { Health System Responsiveness' subscale 7.4-7.5 } \\
\text { (Q7100-Q7107) questionnaire }\end{array}$ \\
\hline Efficiency & $\begin{array}{l}\text { Flow, length of stay, crowding and reasons for } \\
\text { crowding, providers' perception of managing } \\
\text { high workflow }\end{array}$ & $\begin{array}{l}\text { The numbers of patients and a variety of time } \\
\text { variables of length of stay will be retrieved from the } \\
\text { database of emergency. } \\
\text { How nurses in charge and doctors on call perceive } \\
\text { their abilities in managing several patients at the } \\
\text { same time (Doyle et } a l^{31} \text { ) }\end{array}$ \\
\hline $\begin{array}{l}\text { Interprofessional } \\
\text { trust }\end{array}$ & Characteristics of interprofessional trust & $\begin{array}{l}\text { Purposeful sample; focus group interviews with } \\
\text { doctors on call and nurses in charge }\end{array}$ \\
\hline \multicolumn{3}{|c|}{ Formative evaluation } \\
\hline $\begin{array}{l}\text { Reflection and } \\
\text { learning }\end{array}$ & Dialogue meetings & Document analysis of dialogue meetings \\
\hline Quality & Performance of clinical leadership & $\begin{array}{l}\text { Convenience sample; shadowing doctors on call and } \\
\text { nurses in charge }\end{array}$ \\
\hline Efficiency & Flow and length of stay & $\begin{array}{l}\text { The number of patients and a variety of time } \\
\text { variables of length of stay will be retrieved from the } \\
\text { database of the emergency department. }\end{array}$ \\
\hline
\end{tabular}




\section{Formative evaluation}

The formative evaluation includes the dialogue meetings, efficiency and characteristics of how CL is performed by nurses in charge and doctors on call after participating in the CLT course. Data from the dialogue meetings that describe organisational processes taking place and changes during the period will be analysed using document analysis. ${ }^{34}$

Shadowing nurses in charge and doctors on call has been conducted to explore how CL is performed. ${ }^{35}$ Shadowing is a research technique that involves a researcher closely following a member of an organisation over an extended period of time. ${ }^{35}$ The method can "produce the sort of first-hand, detailed data that gives the researcher access to both the trivial or mundane and the difficult to articulate'. ${ }^{35}$ To confirm the validity of the data, all participants read the field notes and give their feedback. ${ }^{35}$

Efficiency includes the number of patients admitted to the ED and a variety of time variables of length of stay (ie, arrival at triage, arrival at provider and arrival at doctor). ${ }^{31}$ The time variables have been retrieved from the database of ED.

\section{Intervention: CLT course}

The overarching vision of the CLT course is to establish bedside values and an understanding of excellent day-to-day CL in teams, executing CL with existing resources and within the organisational structure. The development of the CLT followed the seven factors outlined by Salas $e t a l^{36} \mathrm{cf}^{13}$ The didactic model of rela$\operatorname{tion}^{37}$ has guided the design of the course (figure 2). Further, the goals of intervention have been linked to the vision and overarching goals of the hospital. ${ }^{36} 38$

The CLT course encompasses the six factors described by Hiim and Hippe. ${ }^{37}$ All factors are mutually dependent; changes in one feature will have consequences for the other features.

Required resources and time commitment were secured by the steering committee and the decision to allocate 3 days for the pilot course plus four group meetings and a facilitated session over a 2-month period. ${ }^{36}$

Competence was ensured by a faculty consisting of individuals with a background in medicine, leadership, paramedics, pedagogy, emergency care nursing and research. ${ }^{37}$ Three faculty members had long experience as simulation facilitators and Train the Trainers course instructors (EUSim). To ensure understanding and relevance, the faculty also reviewed adverse events reports in the ED and took observational shifts prior to designing the workshops and scenarios. To guarantee a sustainable course and relevance to clinical practice, buy-in and ownership were secured by recruiting former course participants as future trainers. ${ }^{36}$

The overarching vision of the CLT course is to establish bedside values and an understanding of excellent day-to-day CL in teams, executing CL within existing resources and organisational structure. The specific

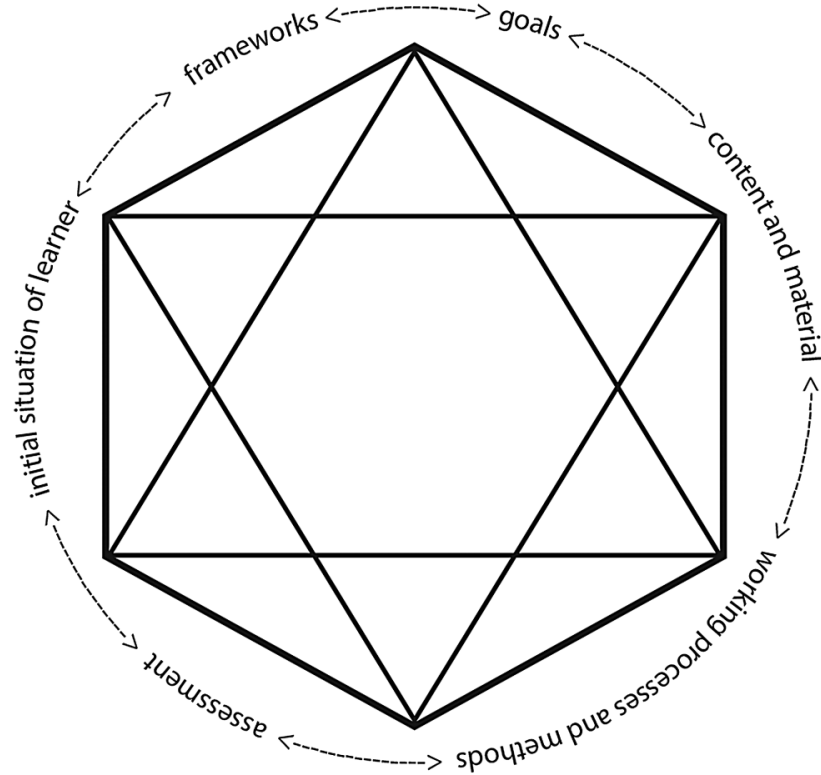

Figure 2 Illustration of the didactic model of relation (Hiim and Hippe ${ }^{37}$ ).

objectives of the CLT for participants are to (1) function as skilled operative leaders and clinical supervisors within their clinical everyday setting, (2) understand and improve patient safety and quality, (3) understand the dynamics of patient flow, and critically and efficiently use available resources and (4) improve trust between health personnel.

In developing the course content, both in materials and subject matter, five main contextualised topics were established: basics, behaviour, team, safety and tools. From these, subtopics were then derived. The CLT course is structured in four steps comprising introduction, theory, workshop/simulation and implementation. ${ }^{13}$ The simulation scenarios focus on limited trauma with chest pain, lack of resources and overcrowding, prolonged length of stay in the ED, unclarified patients, bullying at work and medication error with consequences (for details, see Olsen et $a l^{13}$ ). The simulation sessions were developed by analysing challenging clinical settings and patient scenarios relevant to the department in question. These were identified through precourse discussions and the active use of the hospital incident reporting system.

Pedagogical methods include workshops, simulation, group counselling and peer-to-peer dialogue, all of which emphasise guided reflection. ${ }^{39-42}$ The last two methods were chosen to support the implementation of CL (table 1) and to facilitate the application of trained CL skills on the job. ${ }^{36}$

\section{Statistical analysis}

Multilevel analysis will be performed to analyse the results. Common descriptive statistics with frequencies, per cent, mean and SD will be conducted to describe the study sample on the cluster level. The differences in the outcomes measures will be evaluated on a team or 
individual level. Differences in the distribution of sex, age groups, level of education, etc, and results from the QPP questionnaire between pretest and post-test will be analysed by Student's t-test, the Mann-Whitney test and analysis of variance (ANOVA). To identify differences between the percentages of patients admitted to different specialties and triage codes, the $\chi^{2}$ test will be used. The $\chi^{2}$ test will also be conducted to identify differences between the pretest and post-test in time variables. Correlations will be used to analyse the difference in assessment of crowding from doctors and nurses. All analyses will be carried out using the Statistical Package for Social Sciences, SPSS V.20. A $p$ value $<0.05$ is regarded as statistically significant.

\section{Qualitative data analysis}

To ensure trustworthiness in the analysis, analyst triangulation and member checks will be applied. ${ }^{43}$ The research team will discuss and refine the analysis according to the research questions and themes emerging in the data. The FGI will be analysed by conducting content analysis. ${ }^{44}$ The summary of the dialogue meeting will be analysed using document analysis. ${ }^{34}$ The summaries will act as important data material in the formative evaluation of organisational processes taking place and changes during the study period.

The analysis of shadowing doctors and nurses will be conducted by the first author. The method described by Coffey and Atkinson ${ }^{45}$ will be used to analyse and interpret the data.

\section{Dissemination}

Results of the CLT course study will be reported according to a predetermined publication policy approved by all the members of the research team. Study results will be disseminated via scientific conferences and publications; presentations to healthcare providers, and meetings with stakeholders.

\section{Study status}

The CLT course study run-in period began in August 2013. Data collection will continue until June 2016.

\section{DISCUSSION}

The discussion of the study protocol has been structured in three parts, including discussion of the study design, outcome criterion and the CLT course (the intervention).

\section{Study design}

The strengths of trailing research design is the flexible use of knowledge collected through participation and dialogue in combination with knowledge acquired and interpreted through traditional scientific methods. ${ }^{24}$ Another advantage of trailing research is the capacity to follow-up changes in the project through monitoring, feedback and feed-forward loops. ${ }^{24}$ To improve validity and achieve rigour in trailing research data, the data in this study will be assessed from different sources. The quality of observations will be achieved by prolonged and persistent observations in the ED. ${ }^{46}$ Participatory validity will be obtained by participant confirmation of the 'shadowing' transcription and feedback on results in the dialogue meetings. ${ }^{46}$ Rigour will be achieved based on the transparency with which the data are generated and how events are questioned and interpreted in the formative and summative evaluation.

The challenges with trailing research revolve around the performance of the intervention, finding a good balance between the content of the intervention and the advice given to adjust the intervention based on the results, and the values that guide the advice based on the dialogue meetings. Evaluation will always have a relationship with values. Therefore, it is important to reflect on one's own role as a researcher when entering social processes and how the researcher influences processes. $^{47}$

The literature in trailing research answers questions regarding 'technical' issues, but not how difficult questions linked to researcher relations and roles should be solved in the clinical field. The researcher should be aware of the challenge of shifting between closeness and distance regarding the research as well as feelings related to personal and ethical issues. ${ }^{23} 48$ Usually, this is strengthened if the researcher knows the field, but can, of course, result in confusion if the researcher witnesses unethical practices and acts. The ways the researchers solve difficult situations have consequences for them, the research and the participants.

The study design used here has several weaknesses. ${ }^{49}$ First, the monitoring of time variables, such as length of stay, may be atypical and apart from the mandate. To eliminate some alternative explanations for change in time variables, data have been collected every 6 months over an extended period of one-and-a-half years. Second, any other events (history) between the pretest and post-test, which represent a threat to internal validity, may cause an effect that has alternative explanations. Implementation of similar courses and changes in routines and organisation in the intervention period will be monitored and evaluated as historical threats. ${ }^{50}$ The current design is considered practical in a natural setting, but difficult or impossible to deliver as a random intervention to some people but not to others in the ED. Thus, results are usually less conclusive because causal inferences cannot be made. ${ }^{49}$

\section{Outcome criteria}

Establishing the outcomes of the intervention was challenging, partly due to the length and complexity of the causal chains linking interventions with outcomes. ${ }^{51}$ Additionally, the effectiveness of training programmes is more difficult to measure because a wide range of variables unrelated to the training intervention can mediate both the training process and the outcome. Drescher 
et a $\tilde{l}^{2}$ suggest that these variables need to be considered if it is to be established whether an outcome is due to the training interventions or other unrelated factors.

The outcome of this study is linked to four values outlined in the theoretical framework. Since the main purpose of the intervention is to improve quality of care and patient safety in the ED, it is critical that patientcentred outcomes such as experience and quality of care should be taken into account. ${ }^{51} \mathrm{~A}$ number of instruments exist to measure patient-reported outcomes, such as the Patient Judgements of Hospital Quality. ${ }^{53}$ In Norway, only a few instruments measuring patientreported outcomes have been translated and validated. Instruments measuring satisfaction/quality of care for patients admitted to the ED are rare. ${ }^{54}$ Therefore, the QPP survey ${ }^{27}$ was considered appropriate for acutely ill patients 24 hours after admission in the ED. The lack of patients' experience of their illness in the survey may have increased the risk of bias. Although $\mathrm{TEAM}^{29}$ was constructed to observe critical emergency teams, the instrument was considered manageable and suitable for observing quality of team performance in all teams in the ED. The fact that a variety of time variables have been used to measure efficiency in the ED helped decide how to measure efficiency. ${ }^{54}$ Interprofessional trust is not a well-studied phenomenon in the $\mathrm{ED},{ }^{56}$ which implies a qualitative, explorative design to capture the experiences of interprofessional trust among doctors on call and nurses in charge. ${ }^{49}$

\section{The intervention}

Several factors may influence the effectiveness of the intervention. ${ }^{57}$ Consequently, several aspects of the intervention need to be assessed and evaluated. ${ }^{50}$ The aspects include assessment of learning needs, duration of educational activity, group composition, active participants and use of opinion leaders. ${ }^{57}$

Previous research demonstrates a mixed picture regarding the impact of assessment of learning needs, from no consistent effect to significant effect on learning. ${ }^{57}$ The content and format of the CLT course have been developed by the faculty based on the evidencebased factors, ${ }^{36}$ which emphasises organisational goals more than individual learner goals. With reference to previous research, the result of the study can go both ways. In this regard, the participants' motivation can be significant in the explanations of the study results. ${ }^{58}$

The duration and frequency of the CLT course will have an influence of effectiveness. One review ${ }^{59}$ demonstrates that continuing education lasting 1 day is less effective than education lasting several days, but little difference exists between education of 2 days and education of longer duration. The process of reflection is considered critical for learning in clinical practice. ${ }^{60}$ To meet the recommendations for the duration of the programme, the CLT course facilitates further reflection in group counselling lasting 3 months. A sustainable change in how CL is performed by doctors and nurses will be demonstrated by the study results. Nevertheless, to create a successful, large-scale improvement programme in the long-term requires administrative and organisational implementation strategies in the hospital. ${ }^{57}$

Group composition has an impact on the effect of the CLT course, where participants from one organisation are preferable. ${ }^{57}$ The departmental management selects the participants in the CLT course. Doctors represent the medical, surgical and neurological departments while all nurses represent the ED. Future evaluation will demonstrate whether the selection process and participants from different cultures with different motivations will have an impact on the results. Another factor that has an impact on the effectiveness of the intervention is active participants. ${ }^{57}$ Participants are active in large parts of the CLT course, and the educational activities are therefore consistent with existing knowledge.

The last factor that may have a moderate influence on the results is the use of opinion leaders. ${ }^{57}$ Opinion leaders have different roles, and structured methods are available to identify them. Since departmental management selects the participants in the CLT course, this factor has not been carefully considered. In future, such consideration may decide which faculty members are chosen to conduct new courses.

The results of the study will allow a greater understanding of whether the intervention is effective and how the CLT course tailored for the ED will have an impact on changes in the course curriculum, changes in the study protocol and in procedures in the ED and other units. Finally, our results will be useful to the steering committee and the top leadership of the hospital in future decisions and the distribution of the CLT course in the departments of medicine and surgery. The results will contribute to the bank of available research data that can be used to develop better healthcare services for patients admitted to hospitals.

\section{Author affiliations}

${ }^{1}$ Department of Health Studies, Faculty of Social Science, University of Stavanger, Stavanger, Norway

${ }^{2}$ Department of Surgery, Stavanger University Hospital, Stavanger, Norway ${ }^{3}$ Emergency Department, Stavanger University Hospital, Stavanger, Norway ${ }^{4}$ Global Health Priorities Research Group, Department of Global Public Health and Primary Care, Center for International Health, University of Bergen, Bergen, Norway

Contributors SEH drafted the manuscript. SEH and ØEO participated in the design of the study and performed the qualitative analysis, and SEH performed the quantitative analysis. SEH and ØEO have provided input, protocol and study design revision. Both the authors read and approved the final manuscript.

Funding This work was supported by Stavanger Acute Care Research Group (SAR). Open access publication is funded by the University of Stavanger.

\section{Competing interests None declared.}

Ethics approval The ethics committee of the western part of Norway and the hospital have approved the study.

Provenance and peer review Not commissioned; externally peer reviewed.

Data sharing statement Additional unpublished data from the study will only be available for the authors of the manuscript. 
Open Access This is an Open Access article distributed in accordance with the Creative Commons Attribution Non Commercial (CC BY-NC 4.0) license, which permits others to distribute, remix, adapt, build upon this work noncommercially, and license their derivative works on different terms, provided the original work is properly cited and the use is non-commercial. See: http:// creativecommons.org/licenses/by-nc/4.0/

\section{REFERENCES}

1. Phillips N, Byrne G. Enhancing frontline clinical leadership in an acute hospital trust. J Clin Nurs 2013;22:2625-35.

2. Dickinson H, Ham C. Engaging doctors in leadership: review of the literature. Health Services Management Centre, University of Birmingham, 2008.

3. Swanwick T, McKimm J. Clinical leadership development requires system-wide interventions, not just courses. Clin Teach 2012;9:89-93

4. Mannix J, Wilkes L, Daly J. Attributes of clinical leadership in contemporary nursing: an integrative review. Contemp Nurse 2013;45:10-21.

5. Milton-Wildey K, O'Brien L. Nursing care of older patients in hospital: implications for clinical leadership. Aus J Adv Nurs 2010;28:6-16.

6. Busari JO. Management and leadership development in healthcare and the challenges facing physician managers in clinical practice. Int J Clin Leadersh 2012;17:211-16.

7. Blumenthal DM, Bernard K, Bohnen J, et al. Addressing the leadership gap in medicine: residents' need for systematic leadership development training. Acad Med 2012;87:513-22.

8. Mitka M. Hospitalizations for extreme conditions mean extreme expenses, study verifies. JAMA 2010;304:2579-80.

9. Doan Q, Sabhaney V, Kissoon N, et al. A systematic review: the role and impact of the physician assistant in the emergency department. Emerg Med Australas 2011;23:7-15.

10. Olsen S, Neale G. Clinical leadership in the provision of hospital care. BMJ 2005;330:1219-20.

11. Ferguson L, Calvert J, Davie M, et al. Clinical leadership: using observations of care to focus risk management and quality improvement activities in the clinical setting. Contemp Nurse 2007;24:212-24.

12. Davidson PM, Elliott D, Daly J. Clinical leadership in contemporary clinical practice: implications for nursing in Australia. J Nurs Manag 2006;14:180-7.

13. Olsen Ø, Husebø S, Qvindesland S, et al. Redefining clinical leadership for team-course development. J Hos Adm 2015;4:52-60.

14. Patton D, Fealy G, McNamara M, et al. Individual-level outcomes from a national clinical leadership development programme. Contemp Nurse 2013;45:56-63.

15. Cole $\mathrm{E}$, Crichton $\mathrm{N}$. The culture of a trauma team in relation to human factors. J Clin Nurs 2006;15:1257-66.

16. Cleary M, Freeman A, Sharrock L. The development, implementation, and evaluation of a clinical leadership program for mental health nurses. Issues Ment Health Nurs 2005;26:827-42.

17. Howieson B, Thiagarajah T. What is clinical leadership? A journal-based meta-review. Int J Clin Leadersh 2011;17:7-18.

18. Rocchiccioli J, Tilbury MS. Clinical leadership in nursing. Philadelphia: Saunders, 1998.

19. Cook A, Holt L. Clinical leadership and supervision. In: Holt BDL, ed. Accident \& emergency: theory into practice. Edinburgh: Baillière Tindall Elsevier, 2008:497-503.

20. Stanley D, Sherratt A. Lamp light on leadership: clinical leadership and Florence Nightingale. J Nurs Manag 2010;18:115-21.

21. Harper J. Clinical leadership_-bridging theory and practice. Nurse Educ 1995;20:10-11.

22. Song M, Sandelowski M, Happ MB. Current practices and emerging trends in conducting mixed methods intervention studies in the health sciences. In: Tashakkori A, Teddlie C, eds. SAGE handbook of mixed methods in social \& behavioral research. Thousand Oaks, Calif: SAGE, 2010:725-47.

23. Stensaker IG. Methods for tracking and trailing change. In: Shani $\mathrm{AB}$, Pasmore WA, Woodman R, eds. Research in organizational change and development. Bradford: Emerald Group Publishing Limited, 2013:149-74.

24. Olsen OE, Lindøe P. Trailing research based evaluation: phases and roles. Eval Program Plann 2004;27:371-80.

25. Stensaker IG, Langley A. Comparing change management trajectories in a multidivisional firm. Br J Manage 2010;21:7-27.

26. NBHS, Norwegian Board of Health Supervision in Rogaland. Follow-up evaluation in the emergency department. Stavanger University Hospital, 2013.
27. Wilde Larsson B, Larsson G. Development of a short form of the Quality from the Patient's Perspective (QPP) questionnaire. J Clin Nurs 2002;11:681-7.

28. Grøndahl VA. Patients' perceptions of actual care conditions and patient satisfaction with care quality in hospital. Karlstad: Karlstads Universitet, 2012.

29. Cooper S, Cant R, Porter J, et al. Rating medical emergency teamwork performance: development of the Team Emergency Assessment Measure (TEAM). Resuscitation 2010;81:446-52.

30. WHO DS. A framework for measuring responsiveness. Paper series no 32. Geneva: WHO, 2000EIP/GPE/EBD World Health Organization 2000.

31. Doyle SL, Kingsnorth J, Guzzetta CE, et al. Outcomes of implementing rapid triage in the pediatric emergency department. $J$ Emerg Nurs 2012;38:30-5.

32. Vieth TL, Rhodes KV. The effect of crowding on access and quality in an academic ED. Am J Emerg Med 2006;24:787-94.

33. Morgan DL. Focus groups as qualitative research. Thousand Oaks, Calif: Sage Publications, 1997

34. Duedahl P, Hviid Jacobsen M. Introduktion til dokumentanalyse. Odense: Heraldisk Selskab, 2010.

35. McDonald S. Studying actions in context: a qualitative shadowing method for organizational research. Qual Res 2005;5:455-73.

36. Salas E, Almeida S, Salisbury M, et al. What are the critical success factors for team training in health care? Jt Comm J Qual Patient Saf 2009;35:398-405.

37. Hiim H, Hippe E. Læring gjennom opplevelse, forståelse og handling: en studiebok i didaktikk [Learning through experience, understanding and action]. Oslo: Universitetsforl, 1998.

38. Authority WNRH. Goals and vision. Secondary goals and vision. 2011. http://www.helse-vest.no/english/Sider/health2020.aspx.

39. Schaefer J, Vanderbilt AA, Cason CL, et aliterature review: instructional design and pedagogy science in healthcare simulation. Simul Healthc 2011;6(Suppl):S30-41.

40. Fritze Y, Haugsbakk G. Workshop: interaktivitet, teknologi og læring [Workshop: interactivity, technology and learning]. Oslo: Nettverket, 2000.

41. Shulman L. Dynamics and skills of group counseling. Belmont: Brooks/Cole, 2011.

42. Cox E, Bachkirova T, Clutterbuck D. The complete handbook of coaching. Los Angeles: Sage, 2010.

43. Lincoln YS, Guba EG. Naturalistic inquiry. Beverly Hills, Calif: Sage, 1985.

44. Graneheim UH, Lundman B. Qualitative content analysis in nursing research: concepts, procedures and measures to achieve trustworthiness. Nurse Educ Today 2004;24:105-12.

45. Coffey A, Atkinson P. Making sense of qualitative data: complementary research strategies. Thousand Oaks, Calif: Sage, 1996.

46. Whitney-Cooper C. Action Research. In: Mclntosch-Scott A, Mason $\mathrm{T}$, Mason-Whitehead E, et al., eds. Key concepts in nursing and healthcare research. London: Sage, 2014:67-72.

47. Sverdrup S. Følgeforskning som en nyere tendens i norsk evaluering: Hva er det, og hvordan kan det gjennomføres? In: Halvorsen A, Madsen EL, Jentoft ON, eds.

Evaluering: tradisjoner, praksis, mangfold. Bergen: Fagbokforl, 2013:134-47.

48. Baklien B, Skatvedt A. Forventning og forvirring-følgeforskningens rotete roller. In: Halvorsen A, Madsen EL, Jentoft ON, eds. Evaluering: tradisjoner, praksis, mangfold. Bergen: Fagbokforl, 2013:148-63.

49. Polit DF, Beck CT. Essentials of nursing research: appraising evidence for nursing practice. Philadelphia: Wolters Kluwer/ Lippincott Williams \& Wilkins, 2014.

50. Sidani S, Braden CJ. Design, evaluation, and translation of nursing interventions. Oxford: Wiley-Blackwell, 2011.

51. Datta J, Petticrew M. Challenges to evaluating complex interventions: a content analysis of published papers. BMC Public Health 2013;13:568.

52. Drescher U, Warren F, Norton K. Towards evidence-based practice in medical training: making evaluations more meaningful. Med Educ 2004;38:1288-94

53. Lloyd $\mathrm{H}$, Jenkinson $\mathrm{C}$, Hadi $\mathrm{M}$, et al. Patient reports of the outcomes of treatment: a structured review of approaches. Health Qual Life Outcomes 2014;12:5.

54. Carter EJ, Pouch SM, Larson EL. The relationship between emergency department crowding and patient outcomes: a systematic review. J Nurs Scholarsh 2014:46:106-15.

55. Burström L, Nordberg M, Ornung G, et al. Physician-led team triage based on lean principles may be superior for efficiency and quality? A comparison of three emergency departments with different triage models. Scand J Trauma Resusc Emerg Med 2012;20:57. 
56. Friberg K. Interprofessionell tillit i somatisk akutmottagningvaktledares och vaktläkares erfarenheter. Stavanger, Norway: University of Stavanger, 2015.

57. Wensing M, Fluit C, Grol R. Educational strategies. In: Grol R, Wensing M, Eccles M, et al., eds. Improving patient care the implementation of change in health care (2nd edition). Somerset, NJ: USA: John Wiley \& Sons, 2013:197-209.
58. Hobma SO. Directed self-learning. Maastricht University, 2005.

59. Beaudry JS. The effectiveness of continuing medical education: a quantitative synthesis. J Contin Educ Health Prof 1989;9:285-307.

60. Jasper M, Rosser M. Reflection and reflective practice. In: Rosser M, Mooney GP, Jasper M, eds. Professional development, reflection and decision-making in nursing and healthcare. Chichester: Wiley-Blackwell, 2013:41-82. 